\title{
An Integral Framework for Permaculture
}

\author{
Brad McManus \\ The Sustainability Centre, Thailand
}

\begin{abstract}
This paper presents Permaculture as a systems design approach to working with nature. An Integral framework is applied to identify the current focus of Permaculture and ways for it to become more holistic. In doing so, holons are discussed in the context of the inter-connected nature of our existence. The spiral of development including levels or 'waves' is presented, along with the prime directive of attending to the health of the spiral at all levels or 'waves' and in all lines or 'streams' of development. Without this focus, attempts to see the whole picture may be incomplete and fragmented. An Integral framework for Permaculture is presented. The benefits of adopting such an approach are discussed, along with the role that personal choice and personal responsibility play in pursuit of greater awareness and a more sustainable way of living.
\end{abstract}

Keywords: Integral, Permaculture, Holon, Levels, Lines, Self Awareness, Sustainability

Wisdom demands a new orientation of science and technology towards the organic, the gentle, the non violent, the elegant and beautiful (Schumacker, 1975)

\section{The Current Context and the Integral Permaculture Opportunity}

Human kind currently faces a number of great challenges. These include the need to adapt to a changing and increasingly less hospitable natural environment; food and water shortages; the rapid depletion of non renewable resources and the destruction of natural habitats which maintain balance in the ecological Earth system. Add to these challenges, serious human problems such as violence, corruption, oppression and the misguided exploitation of technology and we are left with both a dilemma and an opportunity. Science and technology alone is insufficient to navigate our way through this crisis. Although valuable, it may only address some of the symptoms and provide some of the answers. What is required is a combination of science and technology, wisdom, morality and the courage to open our minds to a more integrated approach to working with nature and not against it. This paper presents an opportunity to combine two such approaches, Permaculture and Integral theory.

The paper starts by presenting an overview of Permaculture and the principles involved. An Integral framework is then applied as a meta-theory to identify the focus and limitations of the current approach to Permaculture. The Author's main argument is that the current Permaculture approach is predominantly scientific in focus. It therefore lacks consideration of the subjective or interior aspects essential to the proper functioning of natural ecological systems. The subjective aspects of the Integral framework are then explored in more depth from both an individual and collective perspective. In doing so the author draws on theory from culture studies, transpersonal psychology and contemporary philosophy. The paper concludes with the benefits of an Integral framework for Permaculture and identifies some practical ways for the framework to be applied.

\subsection{An Overview of Permaculture}

Permaculture involves the design of sustainable agricultural systems and human habitats that mimic the patterns and relationships found in natural ecologies. The approach seeks to educate people in ways to reduce society's reliance on industrial systems of production that are argued to be systematically deteriorating the Earth's ecosystems (Mollison and Holmgren, 1978). By focussing on a core set of design principles, Permaculture encourages people to design their own environments and build increasingly self sufficient human settlements. It is premised on the redesign of unhealthy systems so they become naturally re-generative and can solve their problems internally.

Permaculture also provides a loosely defined lifestyle philosophy and ethic. The term Permaculture refers to permanent agriculture and permanent culture. The ethical foundation of the approach is to care for people, care for the Earth and redistribute resources surplus to one's own needs (Mollison, 2002). The three ethical principles are considered equal in priority, with an emphasis on respect for all living organisms. Essentially Permaculture adopts a sustainability perspective suggesting that human kind must be prepared to give back what is taken from nature to preserve it for future generations.

\subsection{The Twelve Principles of Permaculture}

Holmgren (2002) identifies twelve principles for the practical application of Permaculture:

1) Observe and interact: By taking the time to engage with nature we can design solutions that suit our particular situation.

2) Catch and store energy: By developing systems that collect resources when they are abundant, we can use them in times of need.

3) Obtain a yield: Ensure that you are getting truly useful rewards as part of the work that you are doing. 
4) Apply self-regulation and accept feedback: We need to discourage inappropriate activity to ensure that systems can continue to function well.

5) Use and value renewable resources and services: Make the best use of nature's abundance to reduce our consumptive behaviour and dependence on non-renewable resources.

6) Produce no waste: By valuing and making use of all the resources that are available to us, nothing goes to waste.

7) Design from patterns to details: By stepping back, we can observe patterns in nature and society. These can form the backbone of our designs, with the details filled in as we go.

8) Integrate rather than segregate: By putting the right things in the right place, relationships develop between those things and they work together to support each other.

9) Use small and slow solutions: Small and slow systems are easier to maintain than big ones, making better use of local resources and producing more sustainable outcomes.

10) Use and value diversity: Diversity reduces vulnerability to a variety of threats and takes advantage of the unique nature of the environment in which it resides.

11) Use edges and value the marginal: The interface between things is where the most interesting events take place. These are often the most valuable, diverse and productive elements in the system.

12) Creatively use and respond to change: We can have a positive impact on inevitable change by carefully observing, and then intervening at the right time.

In summary, Permaculture claims to look at the whole system or problem; observe how the parts relate and connect; and design ways to fix the systematic problem in a long term sustainable manner. This includes recognising patterns in natural ecological systems and learning from past mistakes. The Permaculture approach therefore focuses on what can be observed in the objective, physical realm of nature, effectively a community of organisms or ecological web of life. The question arises; Are we seeing the whole picture through the current Permaculture approach or is there something more, a bigger picture of reality to be considered?

\section{The Structure of Organisms and the Dynamics of Change}

To explore the need for a more complete picture of Permaculture, we first examine how organisms are constructed, interconnected and the dynamics of change in what Permaculture refers to as the web of life or nature systems. Wilber (1996) cites Arthur Koestler (1967) to use the term 'holon' to describe an entity that is itself a whole and at the same time part of some other whole. It is therefore a whole/part. Wilber (2000) states, 'reality is composed of neither things nor processes, neither wholes nor parts, but whole/parts, or holons all the way up and all the way down ... indefinitely and unendingly'. For example, a cell in an organism is a whole. At the same time it is a part of another whole, the organism. Another example, hydrogen and oxygen molecules are each self-existing entities or holons. They are simultaneously integral sub-holons found in water. Without the simultaneous presence of both sub-holons, water would not exist, nor would life on Earth as we know it because although some organisms can live without oxygen, none that are known can survive without water (Morrow, 2006).

Wilber (1996) adds that holons share four common characteristics:

a) Two drives at any level: One drive to maintain it's 'partness' or in other words its autonomy, identity or 'agency', whilst simultaneously an opposing drive to maintain its wholeness (part of other wholes or 'communion'). If it fails at either of these it ceases to exist.

b) Two capacities at any level: The capacity to either transcend or dissolve. On self-transcending the holon goes beyond what went before and becomes more complex, unfolding new patterns of creative emergence. On self-dissolution the holon breaks down in the similar pattern in which it was constructed in the first place, reversing into the sub-holons.

For the purpose of this paper the words holon and self can be used interchangeably. The dynamics are simpler to understand if we consider the four characteristics as 'pulling' the holon or self simultaneously in four opposing directions as shown in Figure 1. Levels are represented by the spiral which is explained in more detail shortly.

It is by the preservation drive that a level is appropriated, developed, consolidated and integrated (Wilber, 2001). It follows that it is by this drive that the self appropriates, develops, consolidates and integrates into a level. In other words the self develops a 'centre of gravity' at that level. The self has the capacity to grow and develop to higher levels once this centre of gravity is achieved. To do this the self must release or let go of its exclusive identification with the lower level (or levels) to allow identification with a higher level. Only then may it transcend to the higher level. On doing so the preceding level is included thus resulting in an expanded, more complex reality.

This is significant to Permaculture for two reasons. Firstly, the dynamics that pull at the self are representative of the dynamics that may be observed in the patterns and functioning of natural ecological systems. As ecological systems evolve, hierarchical patterns and structures unfold and organisms navigate these structures to survive and grow. Secondly, during the past thirty years Permaculture has evolved from a predominantly agricultural 
systems design focus to include ethical ideals of creating sustainable human communities. This is a significant development as it can be argued that human kind doesn't just have ecological problems, we have human problems as well. Given this, a suitable framework is required to better understand the subjective aspects of the social or 'collective' dimension of Permaculture. Such a framework should also include the subjective aspects of the self, both in relation to community and the physical aspects of nature; for example organisms and systems. Without this, the complete picture may not be clearly understood and the current approach of Permaculture to seeing the whole system or problem may be partial and fragmented. Put another way, it is difficult to see the whole picture unless the observer is aware of who they are, the way they view the world and how the inter-subjective cultural factors affect behaviour and the functioning of social systems.

\section{An Integral AQAL (All Quadrants, All Levels) Framework}

To present a complete integrated perspective, Ken Wilber (2000) provides the Integral AQAL framework. Described as a 'meta-theory', it provides a comprehensive map of human capabilities in relation to self, others and the objective world. The quadrants of Integral Theory refer to the fact that all major human languages have first, second, and third-person pronouns (for example I, you/we and it). These three dimensions of reality (I, we and it) often show up as art, morals and science. Including the plural of it, its, gives rise to the four quadrants. Figure 2 illustrates the four quadrants of the Integral AQAL framework.

The quadrants are recognising the inside and the outside of a holon (self) in its individual and collective forms (Wilber, 1996). The two left hand quadrants relate to the inner subjectivity of the self and the inter subjectivity of the collective, or group. The upper left 'I' quadrant represents the subjective intentionality of self; an individual's thought process, values, awareness of self, beliefs and perceptions. The lower left 'We' quadrant represents the social self or sense of self in relation to others and the prevailing culture. Due to their subjectivity, the 'I' and 'We' perspectives are challenging to observe and measure, however given that they form part of reality they do manifest in the physical realm by way of behaviour and social systems.

The two right hand quadrants relate to the exterior or objective physical self. The upper right 'It' represents what is observed behaviourally; the self's skills, abilities and physical expression of values. It is also the physical form of an organism, the anatomy of the self. The lower right 'Its' quadrant symbolises the inter-objectivity between the exterior self and the external environment. Examples include the structure of economic systems, cities, natural ecosystems and communication networks such as the Internet. Both the 'It' and 'Its' quadrants are objective and may be physically observed.

The two upper quadrants, 'I' and 'It' have a singular or individual focus, and the two lower quadrants, 'We' and 'Its', have a plural or collective focus (Wilber, 2000). Each of the four quadrants is essentially a simultaneous facet of reality for the self. The quadrants are irreducible and inter-connected, with the self at the centre of the framework. The reason for this is the self is navigator, with the capacity to push up, pull down, hold on or let go.

The Integral approach acknowledges that these facets of reality are always present and therefore any comprehensive or Integral approach must include all four facets. No quadrant is more or less important than another. An analysis applying any less than the four quadrants is likely to be partial and would therefore inhibit our ability to identify, define and adequately understand a problem, let alone attempt to solve it.

\section{The Current Focus and Limitations of the Permaculture Approach}

Suzuki (1997) states, "scientists focus on parts of nature attempting to isolate each fragment and control the factors impinging on it." The web of life approach, although valuable from a scientific analysis perspective, is reductionist because it acknowledges only the biological and scientific physical realm, thus denying the existence of the non physical, subjective interior of the self. Similarly, Lovelock (2009) presents Gaia theory which sees the Earth as a self-regulating system made up from the totality of organisms, surface rocks, the ocean and the atmosphere tightly coupled and evolving. He goes further to offer a wakeup call for humanity to co-operate with nature, or suffer the consequences, including possible extinction. Lovelock suggests it is not an option to continue with a 'business as usual' approach, or in the words of Albert Einstein, 'The world will not evolve past its current state of crisis by using the same thinking that created the situation'.

Currently, the systems design approach of Permaculture focuses mainly on the 'It' and 'Its' quadrants (the behavioural and systems quadrants). This is because Permaculture emphasises observation, design, planning and behaviours that are beneficial to the natural environment and contribute to developing sustainable communities. This is referring to nature in its objective form, which although a particular strength of the Permaculture approach, is only part of the whole picture. The 'It' and 'It's' perspectives, although essential, are of limited use unless they are viewed in conjunction with the 'I' and 'We' perspectives. Only through the combination of 'I, We, It and Its' may a more expansive and comprehensive Integral perspective be reached. It follows that the foundation of an Integral approach to Permaculture, or sustainable living in general, is to recognise the four quadrants and strive for simultaneous balance between them.

Permaculture acknowledges the 'We' quadrant, but in a limited way at this stage in the evolution of the approach. For example, the Permaculture approach encourages the building of self sufficient communities and the redistribution of goods and resources surplus to one's own needs. These are essentially behaviours and alterative 
systems which represent the 'It' and 'Its' perspectives. Such a perspective pays inadequate attention to people living in a community, the shared values, cultural beliefs, ideals, level of personal development, self awareness, intentionality, and so on. To explain we come back to the Integral model and further explore the ' $\mathrm{I}$ ' and 'We' quadrants.

\section{Further Exploration of the 'I' Quadrant}

The 'I' quadrant is important to Permaculture because it includes an individual's principles and values, intentionality, awareness, intuition, imagination, emotion and compassion for the well being others. It is here that each self has the potential to evolve in terms of consciousness and spiritual awareness. For example, a person is a holon and is fundamentally interconnected with social systems and the natural ecology. Therefore the behavioural choices a person makes in any given moment of time affects the functioning of the entire system. This is because human kind is not just an observer of nature, we are part of it and it is part of us. If a person sees Permaculture as a good idea and he or she doesn't see it as part of their being, it will either fade out or become a set of actions without meaning and a flatland type of system.

There is a significant body of literature emphasising the importance of being in and experiencing the present moment (Cacioppe 1997; 2000, Gladwell, 2005, Tolle 2005). This is because it is in this true essential state that the self is both mindfully and spiritually aware, therefore in balance with the four driving forces that pull at it (hold on, let go, push up and pull down). With practice, being in the moment can contribute directly to the self ascending/pushing up the spiral of development. This is explained in more detail shortly. What is important is the self as navigator in life, with the capacity to develop and grow. The ' $\mathrm{I}$ ' perspective influences how an individual may answer questions such as; who am I, why am I here and what does it all mean? The 'I' quadrant is of equal importance to the other three quadrants as it represents our individual capacity to appreciate the beauty of nature, reconnect with and experience it and express our individual creativity. These are positive examples; however the self also has the capacity for pathologies in this quadrant which may lead to imbalances in the other quadrants, including destructive behaviour. Examples include adult hood narcissism, histrionics, greed, intolerance and depression.

Goleman (1995) uses the term 'emotional intelligence' to describe a person's awareness of their own emotions and the emotions of others. He highlights the important role emotions play in one's thoughts, decision making and relationships with other people. Goleman identifies self awareness of one's emotions as essential to understanding and constructively dealing with negative emotions that inhibit performance such as stress, anger and fear. Zohar and Marshall (2000) present another perspective and apply the term spiritual intelligence. They identify seven practical steps to improve spiritual IQ. These are:

1) Become aware of where I am now

2) Feel strongly that I want to change

3) Reflect on what my own centre is and what are my deepest motivations

4) Discover and dissolve obstacles

5) Explore many possibilities to go forward

6) Commit myself to a path

7) Remain aware there are many paths

The emotional and spiritual intelligence examples relate directly to Holmgren's (2002) Permaculture principles of 'applying self regulation and feedback' and 'creatively using and responding to change'. The current approach to Permaculture applies these two principles to 'looking outward' or observing the 'It' and 'Its' perspectives of reality. What's missing however is deeper understanding that a person also has the capacity to look inward, reflect, learn, develop, realise and correct negative thoughts and destructive behaviours. The degree of self awareness of an individual influences their behaviour, the health of that person, their relationships with others, and the health and functionality of the overall system. Self awareness is therefore of great importance to the teaching and practice of Permaculture.

\section{Further Exploration of the 'We' Quadrant}

Holmgren's Permaculture principle of 'Integrate rather than segregate' can be related to the self in its subjective individual and collective forms. This is because a holon (or self) exists in all four quadrants simultaneously. There is however a distinction between individuals and culture (I and We), and cells and organisms (It and Its). The latter have a physical form and boundary, whereas the individual and culture quadrants do not, they are subjective. Therefore an organism is connected with and part of a social holon only by way of membership, rather than physical form (Wilber, 2010). For example, ecosystems involve individual organisms and groups of organisms. Each individual organism has to varying degrees levels of interior development, such as perception, intentionality and awareness. An organism is a member of the ecosystem in its subjective form, a social holon. The social holon includes shared meaning and understanding between organisms comprising the system. The membership of the organism to the culture may not be observed as it has no physical form, nevertheless it is prerequisite to the survival of the organism and the system. 
The current approach to Permaculture presents two principles that are particularly relevant to the 'We' quadrant. These are 'Use and value diversity' and 'Use edges and the marginal'. Both principles can be expanded to relate to culture, which indeed requires an understanding of diversity. As Holmgren (2002) points out it is the interface between things where the most interesting events usually take place and it is on the edges of nature where often the most valuable, diverse and productive elements in the system exist. This is very similar to the 'We' or cultural quadrant in an Integral approach to Permaculture.

From the many definitions of culture available, it basically comes down to a set of beliefs, values and attitudes shared by a group. This in turn influences perception and derivation of meaning for the group. Several researchers have contributed to a deeper understanding of culture (Hofstede, 1984, Hofstede and Hofstede 2005, Wenger 2000, Triandis 1989, Moore 1997, Trompenaars and Hampden-Turner 1997). Trompenaars and Hampden Turner analyse the basis of cultural differences across nations using seven key dimensions. They argue that the seven dimensions affect how we relate to other people, thus suggesting that culture is a way for a group of people to solve problems and reconcile dilemmas. The dimensions examine the extent to which a person sees themselves primarily as an individual or part of a group, how status is accorded, the depth of involvement during interpersonal contact, whether a culture emphasises rules or relationships, tolerance for ambiguity, masculine versus feminine, attitude toward time, power distribution and sense of control over the natural environment. Such approaches are useful in gaining deeper understanding of the complexity of culture and practical ways to navigate them. However they do not tell the whole story, because they focus on what can be observed and measured, the behavioural manifestations or symptoms of culture, offering little explanation as to contributing factors beneath the surface.

The Permaculture approach acknowledges that all things in nature including the wind, the waves and the earth on its axis moving around the Sun, form patterns. Permaculture designers are encouraged to develop awareness of existing patterns, how these function, and to apply the patterns on sites in order to satisfy specific design needs. It therefore should come as no surprise that patterns of consciousness exist in the interior self, individually, collectively, everything in between, above and below. Is it possible that the patterns are inter-connected, meshed, colliding, dissolving, emerging etc? This is now explored.

\section{The Spiral of Development}

\subsection{Levels of Development}

In addition to the four quadrants, or facets of reality identified by Wilber, the Integral model includes levels of consciousness development, sometimes also referred to as stages, waves or world views. These are structures in the psychological stream of events, in and around which the self can develop and grow, like climbing the rungs of a ladder. Each and every self, whether they are an infant, farmer, student, small business owner or leader of a country has a centre of gravity in a level of development, or in other words a level of development has been reached and is commonly experienced by that person.

Beck and Cowan (1995), Beck (2000) extend the earlier work of C.W. Graves to present Spiral Dynamics. It sees human development as proceeding through at least eight general stages or 'waves' of development that can be expressed in any activity, depending on life needs, problems and challenges that the self (or holon) must deal with. These stages unfold in an ascending, sequential and hierarchical order from physical safety to; being accepted, expressing individuality, maintaining order, achieving success, including everyone, transcending integrating, pure creativity - 'self' realisation. The spiral of development is illustrated in Figure 3.

In the following explanation the words level, stage and wave are used interchangeably. Beck and Cowan point out the levels or stages of development are more like waves and complex meshes; therefore they do not have clearly defined boundaries. The first six levels, beige to green are subsistence or first tier thinking levels. There is then a leap to second tier, into yellow and above where ego may be transcended for an expansive and interconnected perspective or world view. The assumption being that as the level of consciousness increases through each developmental wave, there is a decrease in narcissism. (Wilber, 2000) describes the spiral of consciousness as "a spiral of compassion, expanding from me to us, to all of us...Each succeeding stage incorporates its predecessor and then adds something new...As development moves from pre-conventional to conventional to post-conventional (or from egocentric to ethnocentric to world centric), the amount of narcissism and egocentrism slowly but surely decreases" (pp.21-22). Cacioppe (2000) describes the three same stages as pre-ego - basic instinctive sensory feelings; rational ego - mental/emotional thought; and trans-ego non-dual awareness, at oneness with the world (pg. 111). Implicit in both the Wilber (2000) and Cacioppe (2000) perspectives is that transcendence of ego is the path to greater awareness and a higher level of being. Essentially it represents possibility and hope for humanity to meet the challenges currently faced and emerge from its current state of crisis.

\subsection{Life Needs, Problems and Challenges Experienced at Each Level}

There are certain characteristics in each wave of development that are representative of the world view at that level and how the self responds to the life needs, problems and challenges experienced. These are briefly described. A more in depth explanation can be found in Beck (2000). 
Beige: where there is an automatic instinctive response to ensure survival of physical 'self'. No sense of future or distinct self as the focus is on gratification of immediate needs. Driven by the biological need for survival, avoidance of pain, death or extinction and when dealing with a dangerous external environment where there is competition for food, water and resources. It can be seen in newborn infants, senile elderly, war torn societies and starving masses. "Approximately $0.1 \%$ of the [world] adult population, $0 \%$ power", (Wilber, 2000)

Purple: also referred to as the tribal self where it's 'all for one and one for all' and allegiance is to the extended family, the tribal elders and customs. There is evil and good, mythical spirits and rituals to appease them. Driven by the need to band together for safety and identity, and improve chance of survival by organising people and focussing energy. It can be seen in gangs, sporting teams, native tribes and in third world settings. "10\% of the [world] population, 1\% of the power", (Wilber, 2000)

Red: where the self breaks free from the tribe, is strongly ego centric, expresses impulsively and resists any attempt at control over it. There is survival of the fittest and a need to win and destroy the competition. Anything goes to achieve instant gratification and satisfy the senses. It can be seen in warlords, the military, corporate takeovers, misbehaving rock stars and mankind attempting to conquer nature. "20\% of the [world] population, $5 \%$ of the power", (Wilber, 2000)

Blue: where life has meaning, direction and purpose and the outcomes are determined by an all powerful other or order. The self conforms to the principles of right or wrong, with the faithful rewarded and non conformists rejected. Assigns people their dutiful place according to the 'plan' and sees sacrifice for what is good in the future. It can be seen in parenting, government, patriotism and religious fundamentalism. " $40 \%$ of the population, $30 \%$ of the power", (Wilber, 2000)

Orange: where the self escapes the 'herd mentality' and seeks the best way to achieve individual freedom, autonomy and success. Analysis, strategy and technology are manipulated to achieve objective material success. A competitive environment where winners gain perks over losers. It can be seen in materialism, Wall Street, high performance athletes and the fashion industry. "30\% of the [world] population, $50 \%$ of the power", (Wilber, 2000)

Green: where the self explores inner beliefs and seeks to be equal to others, with a sense of community, co-operation and shared resources. Strongly egalitarian and anti hierarchy, emphasis is on human networking, caring for the disadvantaged, sensitivity to the natural ecology and enriching the human potential. Relationships are priority and decisions are made through consensus to preserve harmony. It can be seen in environmental and community groups, postmodernism, human rights, animal rights and humanistic psychology. " $10 \%$ of the [world] population, 15\% of the power", (Wilber 2000)

Yellow: where life consists of natural hierarchies, systems and forms. Emphasis is on flexibility, spontaneity and functionality to integrate and align systems, and balance the whole. Knowledge and competency supersede power, status or group sensitivity to understand that the prevailing world order reflects the cumulative effects of the first six 'subsistence' levels. The ability to understand and tolerate paradox, enjoy personal freedom without harm to others and see the self as part of a living system. It can be seen in holistic medical practice, holistic governance in Bhutan and leaders such as Nelson Mandela. "1\% of the [world] population, 5\% of the power", (Wilber, 2000)

Turquoise: where the wholeness of existence is experienced through the mind and spirit and the world is seen as a delicately balanced system of interlocking forces in jeopardy at Humanity's hands. Emphasis is on experiencing deeper receptivity of multi dimensional and trans-rational perceptions including the transpersonal, collaborative and interconnected. It can be seen in the beauty of nature, expression of art, collective consciousness and the Dalai Lama "0.1\% of the [world] population, 1\% of the power", (Wilber, 2000)

Spiral Dynamics offers Permaculture an opportunity to add meaning to the way we experience the world. It is directly relevant to the creation of sustainable, self sufficient communities. This is a world we cannot always physically see, but unless we acknowledge that it, or something similar exists, our approach will remain partial, fragmented or broken. Following is a brief explanation of the basic tenets on which the Spiral Dynamics model is based.

\subsection{The Basic Tenets of the Spiral Dynamics Model}

The prime directive of Spiral Dynamics is to tend to the health of the entire spiral. This includes tending to the healthy development of self in relation to all four quadrants, at all levels of development and in the individual, collective, subjective and objective aspects. Colours are used to distinguish or classify the levels, rather than attempting to classify people, thus reducing potential for conflict. Or as Beck puts it, "The focus is not on types of people, but types in people". Each and every individual has all of the levels potentially available to them. The levels are reached however through a sequentially unfolding process of development. An individual or a collective has a centre of gravity most often experienced. Basically the self can experience or 'access' levels beneath, but not above the self's current level. So, one can't just skip a level here or there.

The stages or waves are neither rigid nor clearly distinct levels. As the self develops it transcends the preceding level and includes it to create a more complex consciousness, hence the 'wave' analogy. The higher up the spiral 
the more complex it becomes. The first six levels are first tier, and levels above are second tier. The majority of the world experiences first tier reality. Paradoxically in second tier although complexity increases, the pieces start to come together and simpler solutions become accessible. Moving up or down the spiral, the levels or stages show a pattern alternating between an individual and a collective focus, which also reflects shifts between competitive and cooperative drives and behaviours. This organising principle is illustrated in Figure 4.

An individual or collective may simultaneously access multiple levels up to their level of development and depending on the life needs, problems and challenges faced. For example the self may have a centre of gravity in green, but when faced with a life threatening situation may access any level all the way down to beige to ensure survival. Importantly however, although one may intellectually understand a level it doesn't necessarily mean that the self is at that level. Cognitive understanding and consistently experiencing are different. Wilber (2000) adds that, levels are earned through hard work whereas partial experiences or altered states of consciousness are temporary. The spiral is open ended with the possibility of more levels ahead. The eight mentioned here are presented because they have emerged already, the higher ones most recently and to a lesser extent.

\subsection{Implications for the Practice of Permaculture}

The self, in its individual and collective interior forms, practically translates what is experienced into behaviour and the inter-objective physical environment. It is the behaviour demonstrated daily and the personal choices an individual makes that can either have a positive or a negative effect on the self, others, society and the natural environment. Where there is contradiction or disparity between awareness, intent and the manifest behaviour, there is a pathology or illness, something out of balance. To put it another way if what we do does not reflect what we say or is not congruent with our beliefs and values then it is not authentic. Permaculture applies observation, education and design principles to fixing the health of systems in the physical realm. This is compatible with what is presented in Spiral Dynamics in relation to the non physical or social and spiritual realm. The Integral framework therefore compliments the current approach to Permaculture by demonstrating the interconnectedness between the objective and subjective perspectives of reality. This enables a broader definition of nature, beyond the scientific organism and web of life.

\section{Lines or 'Streams' of Development (How a Level is Reached)}

Wilber (1996) identifies that every holon or self has numerous lines of development, sometimes also referred to as paths, streams or intelligences. These lines or paths are present in all four quadrants of the self (holon) and develop to different extents according to different dynamics, representing an uneven and non linear pattern unique to each individual's development. Some may be highly developed, others poorly developed. Nevertheless the overall level or stage of development (e.g. blue, orange, green etc) of self is the 'sum' of these lines. Wilber (1999) cites the Piaget, Kegan, Kohlberg et.al to note that the development lines themselves unfold sequentially depending on the level of ego development. He adds that over two dozen lines of development have been identified including cognitive, moral, emotional, spiritual, affective, creative, sexual, to mention a few. Figure 5 illustrates in a simplistic way the relationship between lines and levels, although it is improbable they exist in such a parallel and linear fashion, hence the 'stream' analogy.

This is significant to the current approach to Permaculture for a number of reasons. Firstly, how we cognitively, morally, emotionally etc interpret a situation defines how real it is for us, and how we respond. Remember the sum of the developmental lines equates to the level of development. For example, an individual with a centre of gravity in 'green' level is likely to perceive and experience a higher level of cognitive development to an individual existing in the blue or orange levels, which includes a large number governments and business organisations. Therefore the interpretation of meaning will differ dramatically as will the responses by individuals and groups at the various levels. This has implications for the teaching of Permaculture, government and/or corporate support, communication strategies, potential for conflict and so on.

Secondly, the current approach to Permaculture presents a set of loosely defined ethical principles. The Permaculture literature lacks rigour in relation to what these ethics may mean to various individuals and societies and how they may be practically applied. Spiral Dynamics has the potential to add depth and meaning, whilst at the same time including understanding of the lines of development that contribute to the level of development and thus the individual and social experience. Mollison (2002, Pg.1) states the prime directive of Permaculture as, 'The only ethical decision to take responsibility for our own existence and that of our children'. The prime directive of Spiral Dynamics is to tend to the health of the entire spiral in all quadrants, at all levels and in all lines. It follows that personal choice and personal responsibility are fundamental, something that is implicit in the current Permaculture approach but could be made clearer. At this point it is important to note that cognitive development is a prerequisite for moral development and that moral development usually lags one or two levels behind (Wilber, 1999). This is highlighted in the following example.

Monsanto, a company with global operations, generates profit through the patenting of plant life forms and exploiting technology that enables these to be modified or genetically altered. Blazey (2010) explains, Monsanto have trademarked Terminator ${ }^{\circledR}$ technology or 'suicide seeds', whereby these seeds have DNA designed to create sterile seeds by selective programming the plants to kill their own embryos. He cites environmental activist Dr Vandana Shiva who states; "The gradual spread in sterility in seedling plants would result in global catastrophe 
that could eventually wipe out higher life forms, including humans from the planet. Never before has man created such an insidiously dangerous plan to potentially control the livelihoods, food and even survival of all humans on the planet." So how much profit is enough to satisfy the company and its shareholders? Bazely cites the company's 2008 Annual Report to state \$2b US, an increase of $110 \%$ from the previous year. Revenue was also up 36\%. The company's share price in 2002 was $\$ 100$ and in 2008 it was $\$ 938$. In 2009, Monsanto saw record net sales driven by higher 'seeds and traits revenue', or in other words the sale of Monsanto licensed genetically modified seeds and patented biotechnology.

The company's activities and application of biotechnology is controversial and attracting global attention. The example provides insight as to how individual motivation, mindsets and collective world views in the ' $\mathrm{I}$ ' and 'We' quadrants manifest in the physical realm by way of individual and group behaviour, in support of a system that rewards such behaviour. In this example it would seem that the economic system is the predominant driver for Monsanto. The corporate behaviour is indicative of an 'Orange' level of development.

It is beyond the scope of this paper to identify and describe all the lines of development, needless to say they are all vital to the healthy development of the self. It is re-iterated however that each developmental line or stream unfolds sequentially, from egocentric to ethnocentric to world centric. So how can we improve our understanding and learn lessons from the past events, so the patterns of history don't repeat?

\section{Lessons from Failed Past Societies}

There is significant research supporting a view that the once plentiful natural resources required to support human development, such as potable water, adequate food supplies, fertile soil, breathable air and hospitable climates are depleting because they are being used faster than they can be replenished (Suzuki 1997, McDonough and Braungart 2002, Flannery 2005, Abrams 2006, Lovelock 2009).

Hayward (2005) suggests that human kind has become over reliant on human ingenuity and technology to successfully respond to these challenges. Referring to a lack of insight, Hayward cites research by Diamond (2005) into past societies that failed to respond to challenges to their existence including Easter Island, the Anasazi, the Maya and Viking Greenland. He presents four contributing factors:

1) A challenge may not be anticipated before it arrives;

2) A challenge may not be perceived when it does arrive;

3) A challenge may be perceived but not be addressed;

4) A challenge may be addressed but efforts to mitigate it may not succeed. (p.412)

Hayward identifies the first three as failures of insight, the inability of individuals or their societies to act upon challenges to their existence. He attributes this to habits of the mind, language and customs 'blinding' people to what is going on around them and overconfidence in human kind's ability to adapt and apply technology. He argues the development of individual [I] and social foresight [We] could have prevented the failure of those societies. This example highlights the opportunity for the current approach to Permaculture to be expanded to include an Integral perspective.

\section{Conclusion and Application of the Framework}

In keeping with the intent and principles of Permaculture to observe and understand whole patterns, an Integral framework for Permaculture would include:

1) The self as navigator and an understanding of the four opposing drives

2) A four quadrant construct of reality of self in its individual, collective, interior and exterior forms

3) Recognition that 'I' and 'We' are both part of the problem and the solution

4) Levels of development unfolding from the self in a pattern that transcends and includes previous levels

5) Lines or paths of development, the sum of which determines the level of development or world view

6) A prime directive to care for the heath of the entire spiral in all quadrants, at all levels and all lines of development.

The current Permaculture approach is robust from the 'It' and 'Its' perspectives. Further, the focus of Permaculture on observation, design, education and action is conducive to embracing a more expansive and inclusive approach. An Integral perspective provides Permaculture with an opportunity to take an important next step toward a clearer understanding of whole patterns and the role of conscious development, without reducing nature's existence to just the physical realm. In other words, it is an opportunity to make the leap from 'green' to the 'yellow' level, from first to second tier thinking. In an Integral framework for Permaculture, the problems currently faced in ecological systems would be viewed as part of the self, not separate. Therefore people are part of nature, fully interconnected and interdependent. Such an approach would transcend mere observation and systems design, to include experiencing, appreciating and expressing nature as the self in its individual and collective interior forms. It would recognise the self as navigator and therefore self awareness, personal choice and personal responsibility are fundamentally important.

An Integral framework for Permaculture provides an opportunity to better understand the problems, challenges and the potential solutions. Such understanding is critical in terms of tending to the health of the entire spiral, 
because the lower levels have less opportunity, power and freedom of choice. Therefore an inherent responsibility resides with the higher levels to not only be aware of this, but to do something about it.

The current approach to Permaculture acknowledges hierarchies exist in ecological systems and adapts designs accordingly to mimic these patterns. Similar hierarchies exist in the subjective realm, individually and collectively, and specifically in relation to the unfolding pattern of human development through levels in the spiral. It is the sum of the lines of development that determine the level reached. It is the needs, life challenges and problems faced by the self at any given moment in time that determine which level is accessed and how an individual or society responds. An Integral framework for Permaculture offers deeper understanding of the alternating pattern between competition and cooperation as we move through the development levels and, greater awareness of why people respond the way they do in certain situations.

Self awareness is a healthy and necessary part of human development. This includes awareness of the 'I, We, It and Its' aspects of self and recognition that these are all part of us, just as we are part of holons, all the way up and all the way down. Although there is an imbalance in the Earth ecological system, the imbalance in humans is of equal concern in terms of identifying, understanding and fixing the whole problem. This may only be achieved through greater self awareness. Individual self sufficiency and sustainable communities by definition may not be achieved without this understanding. The Integral framework presents an opportunity to expand the current approach to Permaculture and in doing so help people to understand that we ourselves individually and collectively are intrinsically connected with and part of nature.

\subsection{Practical Ways to Apply the Framework in Our Daily Lives}

An Integral approach to Permaculture offers a pointer to the potential that people already possess but are possibly not fully utilising or expressing. When we break from the habits that limit us we open up a world of new possibilities. For example, meditation is simple and practical tool to embrace positive change and in the process let go of negative patterns of the mind, destructive habits and addictions (Batchelor, 2007). For anyone interested in making a change, Figure 6 provides a few examples of ways to practically apply an Integral approach to everyday living. The examples include Permaculture practices and have been expanded to include focus on the self in its interior forms. Implicit here is that one has the will to make a personal choice for change.

While there may be some debate as to which quadrant each example may go in, there is a general agreement on the characteristics of the four quadrants and that they add a greater perspective to any situation. The following passage by Rinpoche (1992, pg.31), encapsulates personal choice, personal responsibility and the self as navigator in life. It is 'An Autobiography in Five Chapters'...

1) "I walk down the street. There is a deep hole in the sidewalk. I fall in.

I am lost ...I am hopeless. It isn't my fault. It takes forever to find my way out.

2) I walk down the same street. There is a deep hole in the sidewalk. I pretend I don't see it.

I fall in again. I can't believe I'm in the same place. But it isn't my fault.

It still takes a long time to get out.

3) I walk down the same street. There is a deep hole in the sidewalk. I see it is there.

I still fall in...it's a habit. My eyes are open. I know where I am. It is my fault.

I get out immediately.

4) I walk down the same street. There is a deep hole in the sidewalk. I walk around it.

5) I walk down another street."

At the beginning of this paper, the need was identified for a more integrated and complete approach to addressing some of the challenges and problems current faced by human kind. This includes combining science and technology, with wisdom, morality and the courage to open our minds to alternative ways of working with nature and not against it. It also requires an expanded awareness, personal choice and personal responsibility to make small changes toward a more sustainable way of life. It is hoped that the Integral framework for Permaculture presented in this paper provides 'food for thought' and a small step in that direction.

\section{References}

Abrams, H. N. (2006). World changing: a user's guide for the $21^{\text {st }}$ century, Harry N. Abrams Inc., New York, NY

Batchelor, M. (2007). Let go: a Buddhist guide to breaking free of habits, Wisdom Publications, Boston, Massachusetts

Beck, D. E. and Cowan, C. (1995). Spiral dynamics: mastering values, leadership and change, Cambridge, Mass: Blackwell Publishers

Beck, D. E. (2000). Stages of social development: the cultural dynamics that spark violence, spread prosperity, and shape globalization, 2000 State of the World Forum, Sept 4-10, NY. NY. 
Blazey, C. (2010). Poor Monsanto, an article published in The Digger's Club - Autumn Garden 2010

Cacioppe, R. (1997). Leadership moment by moment, Leadership and Organization Development Journal, 18/7, pp 335-345

Cacioppe, R. (2000b). Creating spirit at work: revisioning organization development and leadership part II. The Leadership and Organization Development Journal, 21/2, pp 110-119

Csikszentmihalyi, M. (2002). Flow: the classic work to achieve happiness, Rider, London

Flannery, T. (2005). The weather makers: the history and future impact of climate change, The Text Publishing Company, Victoria, Australia

Gladwell, G. (2005). The power of thinking without thinking, Penguin Group, Australia

Goleman, D. (1996). Emotional intelligence: why it can matter more than IQ, Bloomsbury Publishing, London.

Graves, C.W. (1970). Levels of human existence: an open system theory of values, from the Journal of Humanistic Psychology, Fall 1970

Hayward, P. C. (2005). From individual to social foresight, a thesis submitted for Doctor of Philosophy, Swinburne University of Technology, Sept. 2005 leading to publication of Hayward, P. C. (2005), The Worldviews of Foresight, in Slaughter, R. A. (ed) (2005), The Knowledge Base of Futures Studies, 5 vols., CD-ROM, professional edn., Fore-sight International, Brisbane.

Hofstede, G. (1984). Culture's consequences: international differences in work-related values, abridged edition, Thousand Oaks, CA: Sage Publications Inc. Reproduced with Permission of McGraw Hill

Hofstede, G. and Hofstede, G. J. (2005). Cultures and organizations software of the mind: intercultural cooperation and its importance for survival, $2^{\text {nd }}$ Edition, McGraw-Hill, New York, NY

Holmgren, D. (2002). Permaculture; principles and pathways beyond sustainability, Holmgren Design Services, Hepburn, Australia

Koestler, A. (1967). The ghost in the machine, London: Hutchinson. 1990 reprint edition, Penguin

Lovelock, J. (2009). The vanishing face of Gaia: a final warning, Penguin Group, Australia

McDonough, W. and Braungart, M. (2002), Cradle to cradle: remember the way we make things, North Point Press, New York. (pp. 165-181)

Mollison, B. and Holmgren, D. (1978). Permaculture one: a perennial agriculture for human settlements, Transworld Publishers, Melbourne

Mollison, B. (1991). Introduction to Permaculture, Tagari Publications, Tasmania, Australia

Mollison, B. (2002). Permaculture; a designers manual, $2^{\text {nd }}$ Edition, Tagari Publications, Tasmania, Australia

Monsanto Annual Report. (2009). viewed online $10^{\text {th }}$ of May 2010, available: http://www.monsanto.com/investors/financial_reports/annual_report/2009/financial_highlights.asp

Moore, J. D. (1997). Visions of culture: an introduction to anthropological theories and theorists, Sage Publications Ltd, London, UK

Morrow, R. (2006). Earth users guide to Permaculture, Second Edition, Kangaroo Press, Simon and Schuster (Australia Pty Ltd), NSW, Australia

Rinpoche, S. (1998). The Tibetan book of living and dying, Random House Australia Ltd. pp 87-92

Schumacker, E. F. (1975). Small Is beautiful: economics as if people mattered, Perennial Library ed. (New York, 1975), pp 33-34

Suzuki, D. (1997). The sacred balance: rediscovering our place in nature, Allen \& Unwin, Australia

Tolle, E. (2005). A new earth: awakening to your life's purpose, Penguin Books, Australia.

Triandis, H. C. (1989). Cross cultural studies of individualism and collectivism, in Berman, J. (Ed.), Cross-cultural perspectives, University of Nebraska Press, Lincoln, Nebraska.

Trompenaars, F. and Hampden Turner, C. (1997). Riding the waves of culture: understanding cultural diversity in business, $2^{\text {nd }}$ Edition, Nicholas Brearley Publishing, London.

Wenger, E. (2000). Communities of practice and social learning systems, Organization, 7(2), pp. 225-246.

Wilber, K. (2000). A theory of everything: an integral vision for business, politics, science and spirituality, Shambhala Publications Inc., Boston.

Wilber, K. (2000). Integral psychology: consciousness, spirit, psychology, therapy, Shambhala, Boston, Massachusetts.

Wilber, K. (1996). A brief history of everything, Hill of Content Publishing, Melbourne, Australia; Reprinted 1999, National Library of Australia.

Wilber, K. (2001). Eye to eye: the quest for a new paradigm, Third Edition, Revised, Shambala, Boston. 
Wilber, K. (2010). Lines of development and the integral psychograph, [Online] available: $\mathrm{http}: /$ integrallife.com/learn/levels-development/lines-development-and-integral-psychograph.

Zohar, D. \& Marshall, I. (2000). Spiritual intelligence: the ultimate intelligence, Bloomsbury Publishing, London pp225-263.

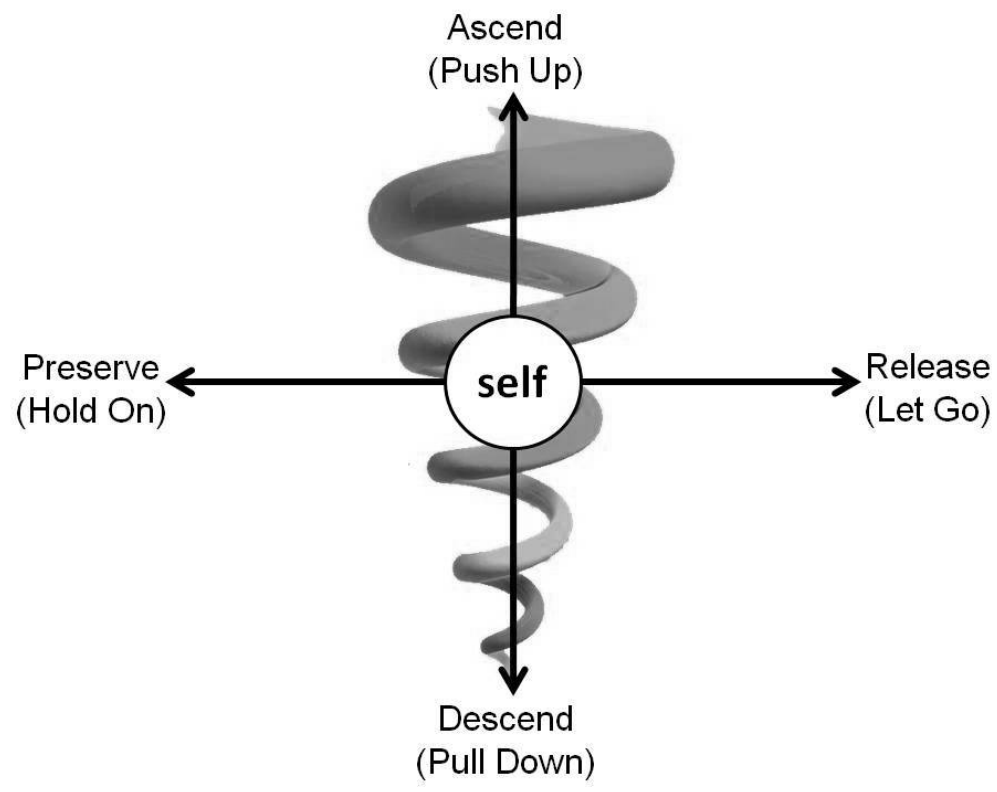

Figure 1. Four Forces Pulling a Holon or Self (Adapted from Wilber, 2001)

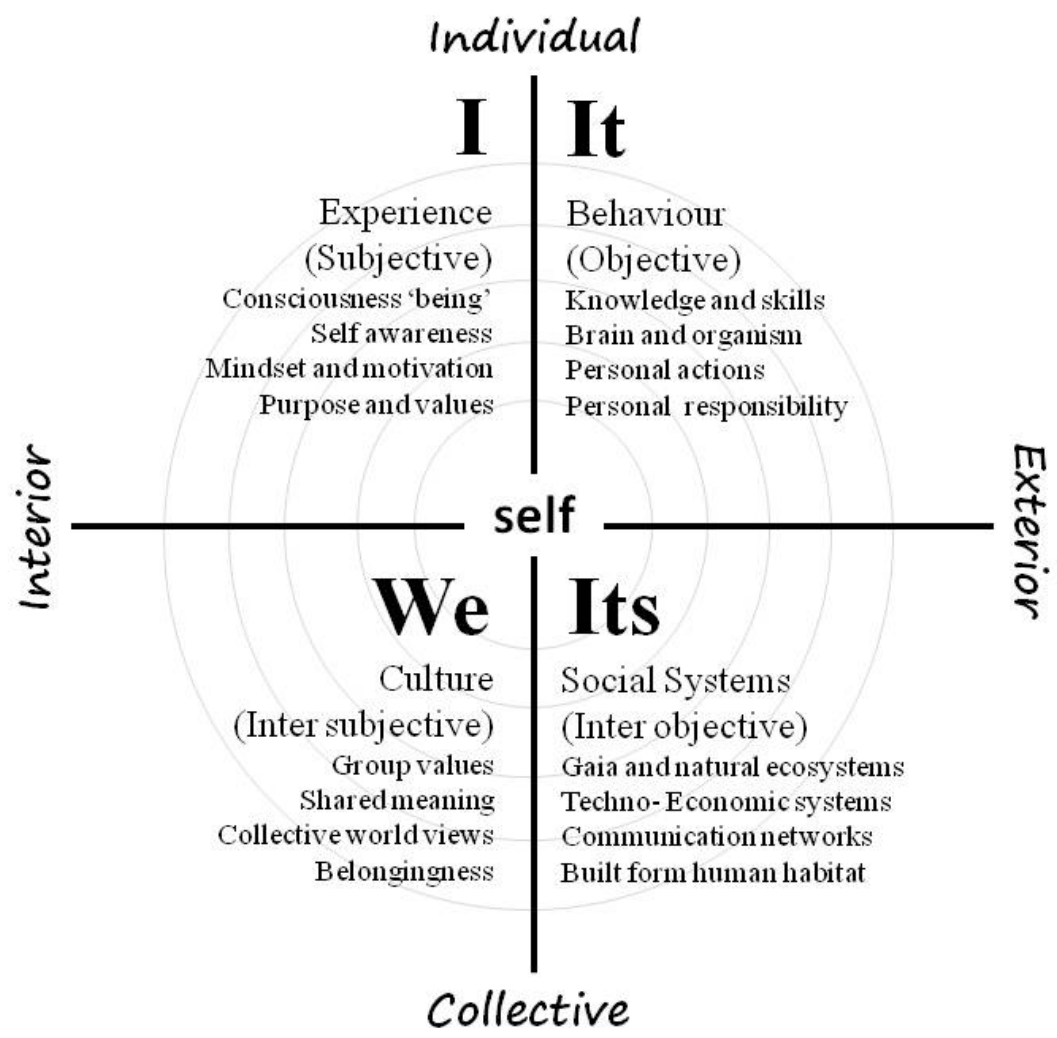

Figure 2. An Integral Framework (Adapted from Wilber, 2000) 


\begin{tabular}{|l|c|}
\hline TURQUOISE & Holistic \\
\hline YELLOW & Integrative \\
\hline GREEN & Communitarian/Egalitarian \\
\hline ORANGE & Achievist/Authoritarian \\
\hline BLUE & Purposeful/Authoritarian \\
\hline RED & Impulsive/Egocentric \\
\hline BEIGE & Instinctive/Survivalistic \\
'World Centric'
\end{tabular}

Figure 3. The Spiral of Development and World Views

"I" Individual (competitive) "We" Communal (cooperative)

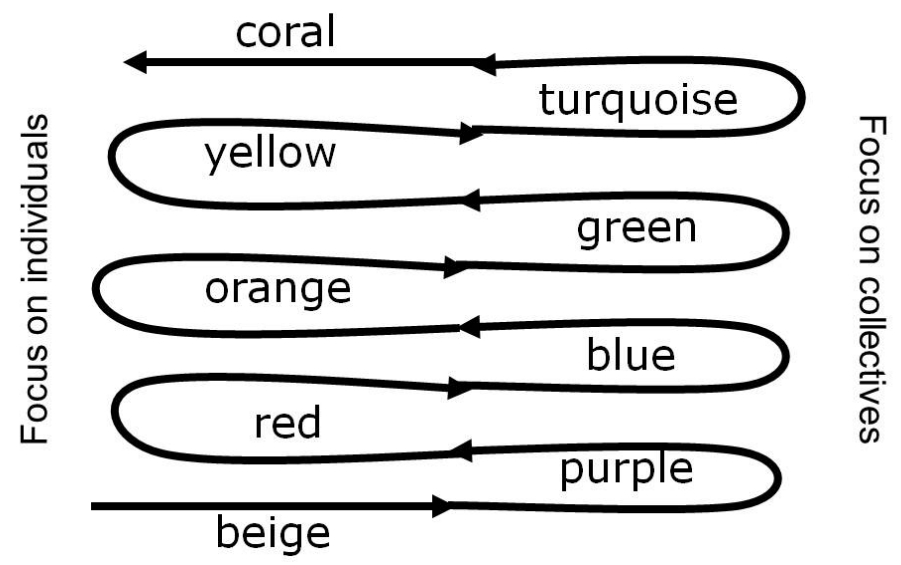

Figure 4. Spiral Dynamic Organising Principle 


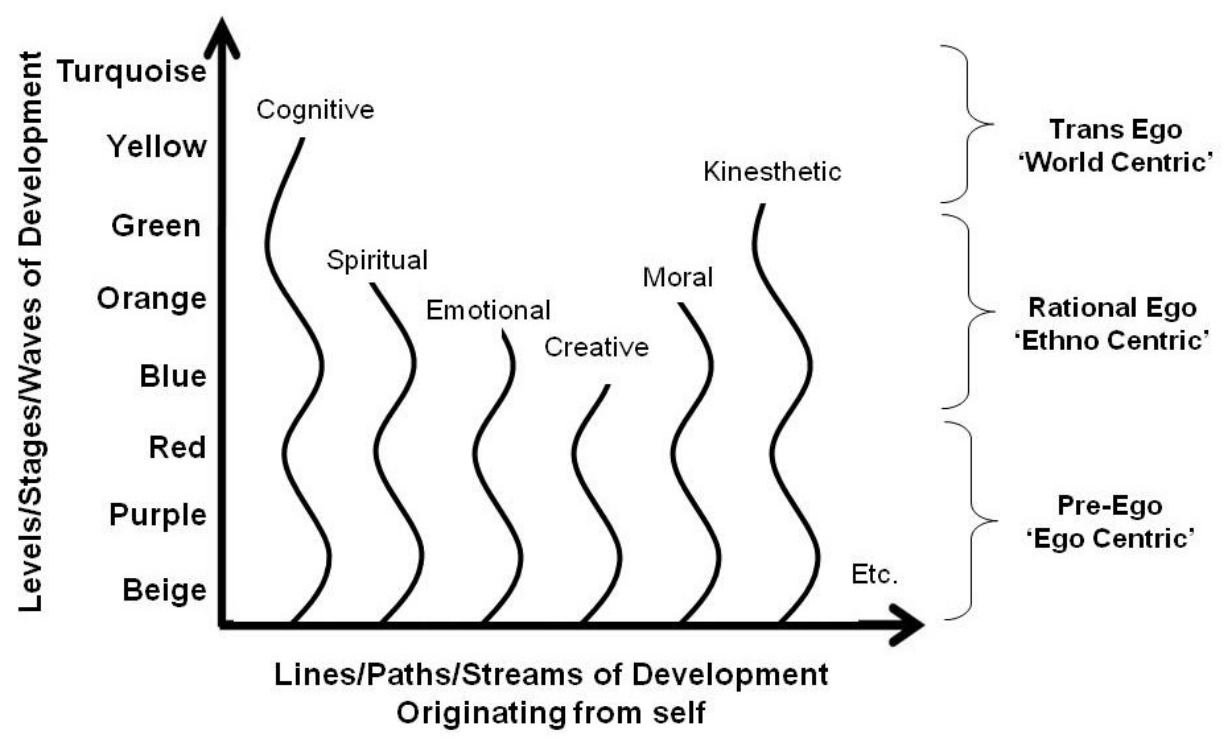

Figure 5. Lines of Development

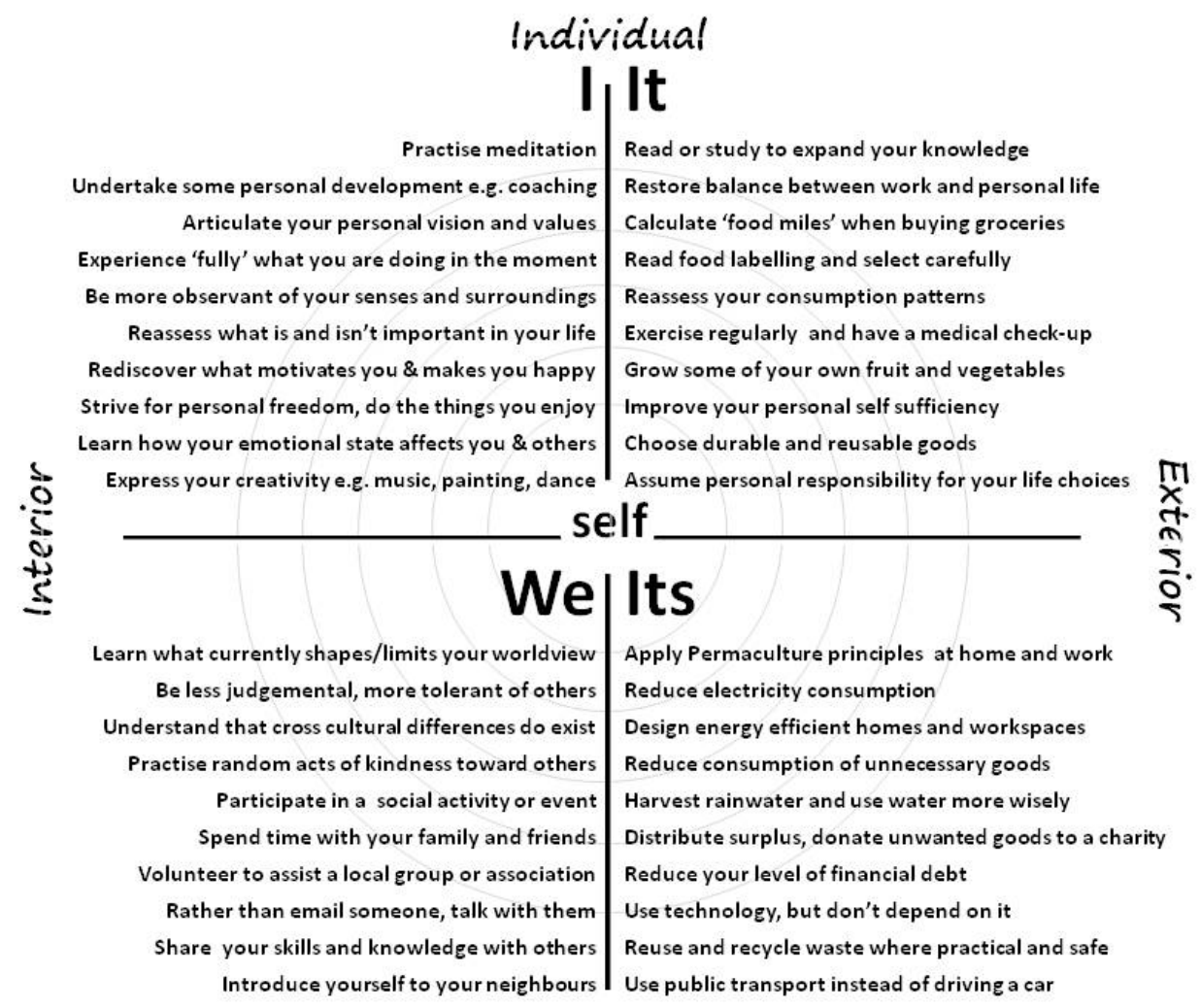

Collective

Figure 6. Practical Ways to Apply an Integral Framework for Permaculture 